\title{
Extended Abstract \\ A METAL ADDITIVELY MANUFACTURED (MAM) HEAT EXCHANGER FOR ELECTRIC MOTOR THERMAL CONTROL ON A HIGH-ALTITUDE SOLAR AIRCRAFT - EXPERIMENTAL CHARACTERISATION
}

\author{
Rafal Wrobel ${ }^{1}$, Ben Scholes ${ }^{1}$, Ahmed Hussein ${ }^{2}$, Richard Law $^{1}$, Ahmad Mustaffar $^{3}$, David Reay $^{3}$ \\ ${ }^{1}$ School of Engineering, Newcastle University, Newcastle upon Tyne NE1 7RU, United Kingdom \\ ${ }^{2}$ HiETA Ltd., Bristol \& Bath Science Park, Bristol BS16 7SR. United Kingdom \\ ${ }^{3}$ David Reay \& Associates, PO Box 25, Whitley Bay NE26 1QT, United Kingdom
}

\section{INTRODUCTION}

This paper describes the testing approach developed for characterizing of alternative integrated heat exchanger (HE) concepts, which are part of the electric propulsion system for a high-altitude solar-powered aircraft. The thermal management of electric motors designed for such an application is particularly difficult due to frequently conflicting design targets like, high levels of integration, low weight and high heat removal capability. Further to these, the operating duty of the high-altitude solar-powered aircraft imposes a number of design challenges. The first challenge is related to the take-off operation, where the motor relatively high-torque demand corresponds to a considerable power loss, which needs to be effectively removed. The high-efficiency operation at cruising altitude is the second challenge, where any redundant system weight has a detrimental impact on the overall flight duration [1]-[3]. It is important to note that this particular aircraft is intended for long-duration endurance flights. Moreover, the environmental operating conditions include both temperature and pressure ranging from $+45^{\circ} \mathrm{C}$ to $-85^{\circ} \mathrm{C}$ and from $101.3 \mathrm{kPa}$ to $5.5 \mathrm{kPa}$ for the sea level and high-altitude $(20 \mathrm{~km})$, respectively.

To assure a reliable thermal design of the propulsion motors, it is essential to account for any manufacture and assembly factors by the use of experimentally derived data from tests on the motor subassemblies and HE prototypes, where appropriate [4]. Such an approach allows for the motor/HE design to be reiterated and adequately adjusted, if required, in a time and cost effective manner. Here, the research focus has been placed on detailed characterizing of the HE exchanger variants, as this design aspect has not been well explored in the context of the electric motors. The decoupled testing of HEs allows for a more insightful analysis, which would be otherwise difficult to perform on a complete motor assembly. In this research, a wind-tunnel like experimental setup has been designed and constructed to map the HE's performance at various operating points including the intake air-speed, dissipated power-loss and airflow patterns. The custom built test rig provides well controlled and repeatable testing conditions, and simple changeover of alternative HE designs. A more detailed description of the testing platform together with selected results from tests on two iterations of the HE design is provided in the consecutive sections of this extended abstract.

\section{METHODOLOGY}

\section{A) Motor Construction}

Fig. 1a) presents a schematic representation of the motor together with integrated HE and outer enclosure. The enclosure's aerodynamic design is to provide sufficient air-flow into the HE body. The complete motor assembly is shown in Fig. 1b). The open-frame motor-housing allows for the air-stream to enter the HE. Fig. 2 shows the fabricated stator core pack and HE assemblies. The HEs have been fabricated using metal additive manufacturing (MAM) to assure all thermal and structural design targets, which would otherwise be difficult to satisfy when using more conventional techniques for manufacturing the HE [8]. Here, aluminium alloy (AlSi10Mg) has been used to construct alternative HE concepts. It is important to note that the HE is required for the take-off operation only. Consequently, it is vital that the HE weight is minimal. An approximate power output per motor is $600 \mathrm{~W}$ at $1000 \mathrm{rpm}$. 
The power delivery during take-off is approximately constant with the initial (sea level) torque demand being 3 times larger than for high-efficiency $(95 \%)$, high-altitude $(20 \mathrm{~km})$ cruise operation. This corresponds to a powerloss at take-off of approximately $250 \mathrm{~W}$ per motor. The majority of the power-loss generated during take-off is associated with the stator-winding assembly (high-torque, low-speed/low-frequency operation). This is where the $\mathrm{HE}$ is particularly important to effectively remove the generated heat. In contrast, the cruise operation (low-torque, high-speed/high-frequency operation) results in various ac effects, which need to be carefully considered to realise the high-efficiency operation [5], [6]. This is notoriously difficult to achieve for small machines/low-power machines. Here, the outer mechanical envelope of active parts is approximately $\varnothing 130 \mathrm{~mm}$ and $30 \mathrm{~mm}$. The highaltitude cruise operation is significantly less demanding in terms of thermal management due both to the environmental conditions and the reduced power-loss.

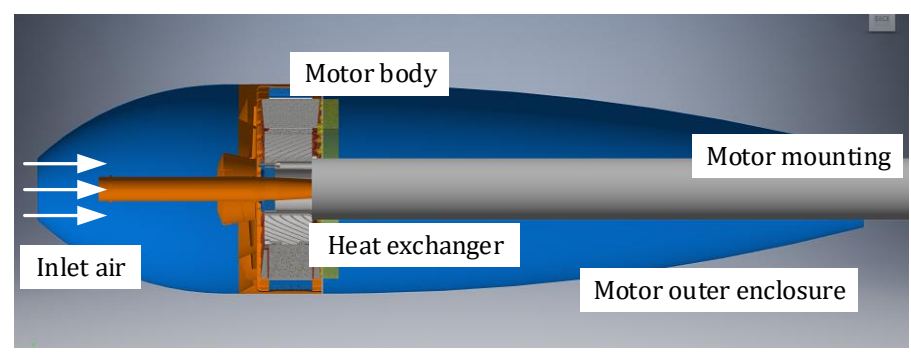

(a)

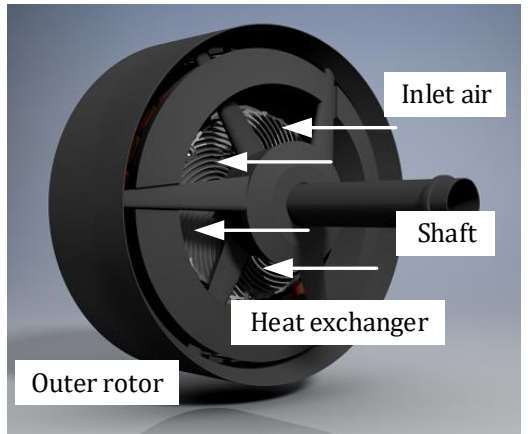

(b)

Fig. 1 (a) The nacelle containing the electric motor and heat exchanger. The aircraft propeller is upstream of the motor. (b) Shows the complete motor assembly.

\section{B) Wind Tunnel Construction and Testing Procedure}

The initial design effort included CFD analyses to examine the flow upstream of the HE, as a degree of 'chaotic' airflow will be introduced due to the rotation of the propeller located between the nacelle inlet and the motor supporting frame, Fig 1b). However, as this aspect of HE operation was not well defined prior to the motor design stage, a simplified approach with well-defined 'straight' airflow has been assumed here. An 'in-situ' analysis of the complete motor assembly with integrated HE, aircraft propeller and outer enclosure would need to be carried out to provide some insight into the 'chaotic airflow'. It is the authors' intention to carry out large-scale wind tunnel tests as development of the aircraft progresses.

The proposed MAM first iteration of the HE, illustrated on the right-hand side of Fig. 2 (a), has been designed to optimise heat removal from the stator-winding assembly during the take-off/ascent phase. A low-scale wind tunnel has been developed to test performance of the HE concepts, Fig. 2b. The key elements of the wind-tunnel include the speed controlled fan, airflow conditioner, airflow speed and pressure measuring instruments, heating element and thermal enclosure. The airflow conditioner includes here is a set of honeycomb and mesh to ensure well-defined 'straight' airflow into the HE body [7]. The flow velocity is measured using both a hot-wire anemometer and a pitot tube allowing one to cross check the measurements. However, due to the relatively small size of the wind tunnel, the pitot tube was preferred as it was less disruptive to the airflow.

As the motor thermal management system harnesses air stream associated with motion of the aircraft, it is important that the pressure-drop across the HE body assures sufficient airflow velocity. To measure the pressuredrop a combination of static pressure probe, pitot tube and micro-manometer was used. The pitot tube was used on the HE inlet to simultaneously monitor the airflow speed, and the static pressure probe was place at the HE outlet. Due to specific 'donut' shape of the HE body a guide to the airflow was introduced. The 'cigar' shaped assembly covering the shaft mounting of the HE assembly is visible upstream of the heat exchanger in Fig. 2b. The heating element was built using an array of surface-mounted power resistors and an interfacing ring. The heating element is supplied from a dc power supply allowing for precise control of the input-power (heat) dissipated by the integrated HE. The outer periphery of the heating element is thermally insulated to ensure one-dimensional heat transfer from the heat source to the heat sink.

The testing procedure includes initial setting the input control quantities, which are the airflow velocity and input power for the heating element. All the quantities including data from thermal sensors are logged using a data 
acquisition system allowing for thermal steady state or transients of the HE to be analysed. The thermal sensors (type-K thermocouples) are placed in several parts of the test rig including the HE, heating element, input and output air. It is important to note that multiple thermal sensors for selected measuring points and are used to provide a more reliable, averaged thermal readings. For the purpose of mapping HE performance, the thermal steady state testing was used. Here, the thermal equilibrium was defined as the temperature change of heating element lower than $1^{\circ} \mathrm{C}$ over 10 minutes. A complete HE performance map includes several inlet airflow velocities and input powers.

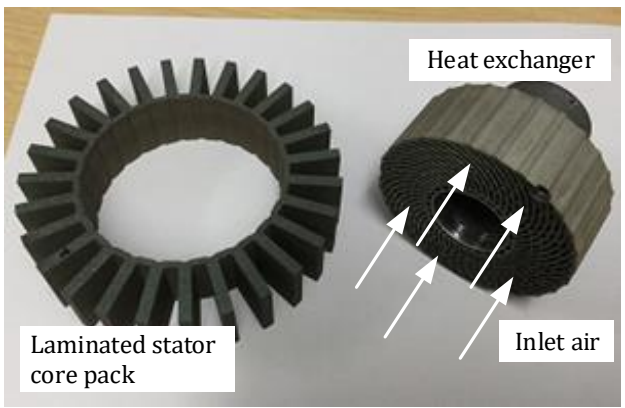

(a)

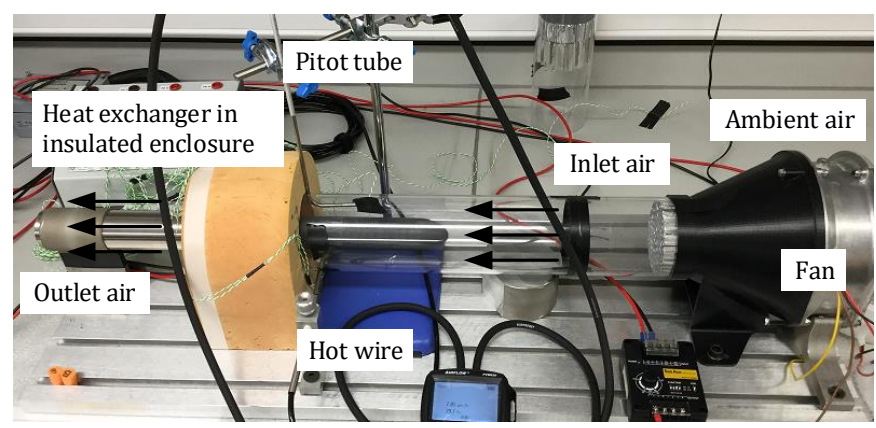

(b)

Fig. 2 (a) Prototype stator core and the MAM heat exchanger. (b) The wind tunnel

Although, the 'chaotic' airflow into the HE body was not specified as a part of this research and development process, the authors made an attempt to account for that effect in the experimental work. The airflow conditioner was removed from the wind tunnel assembly to encourage airflow containing a swirling effect, which is expected for the complete motor assembly with propeller. The axial, propeller-like fan used on the test rig introduces a similar effect. To assess the severity of the airflow swirling, a set of wind-tunnel tests with smoke were carried out. These were performed for both conditioned and unconditioned airflows showing dispersed smoke patterns for the unconditioned airflow. The authors' intention was to capture the smoke patterns to illustrate the swirling effect. Unfortunately, the quality of the smoke used in the experiments did not allow for clear photographs to be taken. However, the airflow pattern had a clear impact on the HE performance, which is discussed in the following section of the extended abstract.

\section{RESULTS AND OBSERVATIONS}

A set of results from characterising of two iterations of HEs is shown in Figs. 3. Fig. 3a) and b) presents variation of the input power versus air-speed into the HE body. The averaged temperature of outer surface of HE is also given in Figs. 3a) and b), see the isotherm contours. The maximum temperature of the heating element provides some indication of how the complete stator-winding assembly would thermally perform. It is important to note that the maximum temperature of the stator-winding is limited by the electrical insulation system used for the winding, here it being class $\mathrm{H}\left(180^{\circ} \mathrm{C}\right)$. The experimental data suggests that the $\mathrm{HE}$ is capable of dissipating the required power loss at air-speeds as low as $1.5 \mathrm{~m} / \mathrm{s}$. This however, would need to be higher for elevated ambient air temperature, e.g. $+45^{\circ} \mathrm{C}$.

It is interesting to note that both HEs perform in a similar manner despite the fact that the second iteration of heat exchanger has reduced active surface area. The initial work on the first iteration of HE has shown that although the design provides required heat removal in principal, the pressure-drop across the HE body is too high to assure sufficient airflow velocity. Consequently, the HE design was reiterated and the second generation of HE was manufactured and tested. As expected, the second iteration of the HE has significantly reduced pressure-drop, by $70 \%$, see Fig. 3c). Also, the overall weight of the HE was reduced by $20 \%$ with an insignificant impact on the heat removing capability at lower airflow velocity Fig. 3d). Fig. 3d) compares results from tests with different airflow patterns, conditioned (CF) and unconditioned (UF). It is evident that the 'chaotic' airflow has a pronounced effect on the overall performance of the HEs. The results show reduced heat removing capability in both cases. However, the first iteration of the HE is more susceptible to airflow with swirl. Here, thermal conductance across from the heating element to the heat exchanger was used. The experimentally derived thermal conductance has been found to be very useful in accelerating the thermal design of electrical machines, where more complex subassemblies like impregnated windings or the HE body can be simplified by a functional representation, e.g. appropriate boundary condition [9]. 


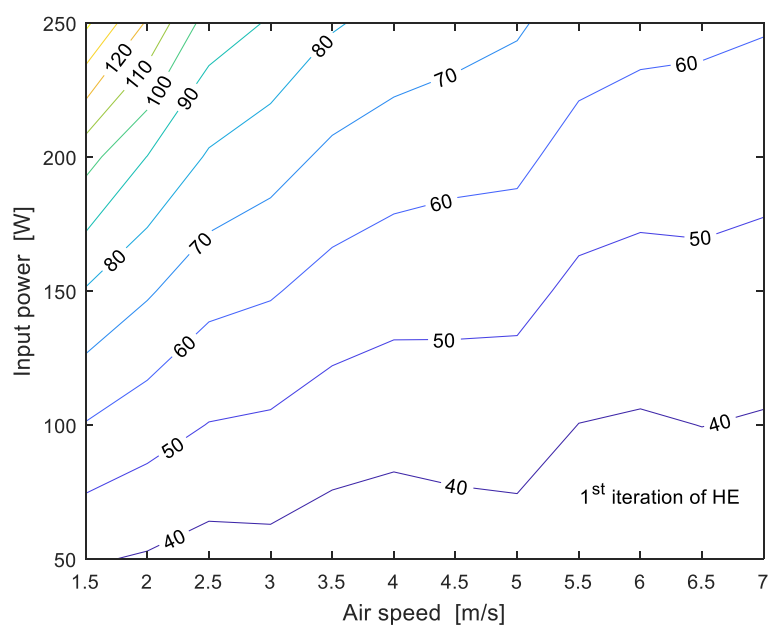

(a)

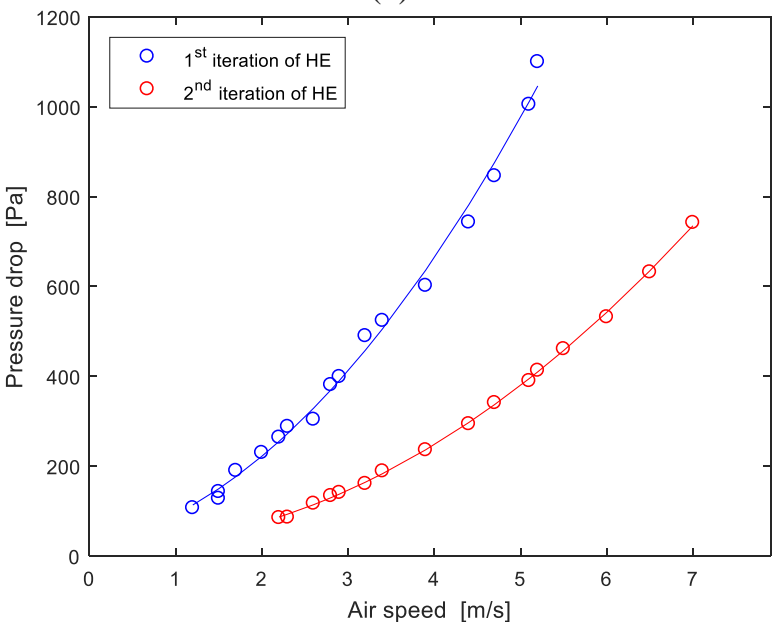

(c)

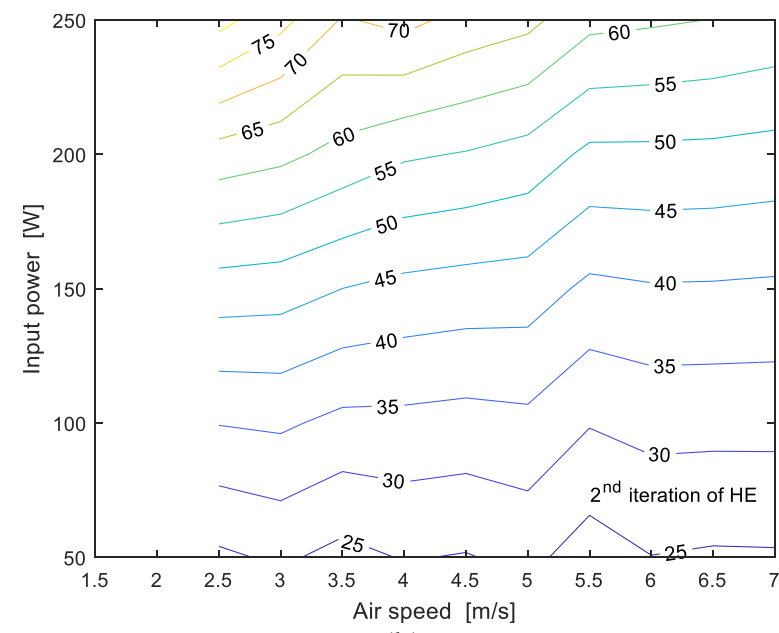

(b)

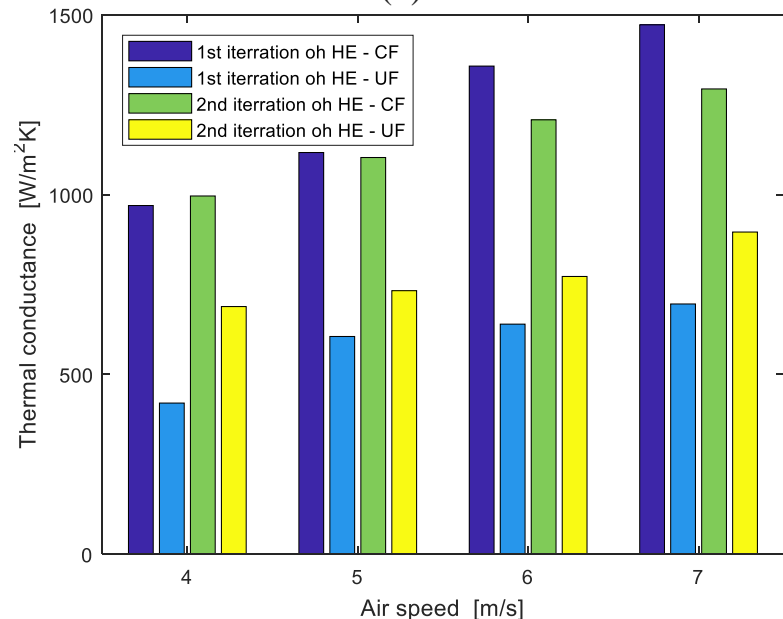

(d)

Fig. 3 Measured data, a) and b) input power into the heating element and HE outer surface temperature (temperature in ${ }^{\circ} \mathrm{C}$ ) versus inlet air-speed $1^{\text {st }}$ (a) and $2^{\text {nd }}($ b) iteration of $\mathrm{HE}, \mathrm{c}$ ) pressure drop across the heat exchangers versus inlet air-speed, d) thermal conductance across heating element and HE

\section{REFERENCES}

[1] S. Ullah, M. Kimiabeigi, B. Scholes, A. Steven, R. Wrobel, W. Davis, J. Widmer, "Optimisation of Permanent Magnet Machine Topologies Suitable for Solar Powered Aircraft," XXIII International Conference on Electrical Machines, ICEM'2018, Alexandroupoli, Greece, September 2018, pp. 332 - 338 [2] J. D. Widmer, C. M. Spargo, G. J. Atkinson, B. C. Mecrow, "Solar Plane Propulsion Motors with Precompressed Aluminium Stator Windings," IEEE Transactions on Energy Conversion, vol. 29, no. 3, September 2014, pp. 681 - 688 [3] B. C. Mecrow, J. W. Bennett, A. G. Jack, D. J. Atkinson, A. J. Freeman, "Drive Topologies for Solar-Powered Aircraft," IEEE Transactions on Industrial Electronics, vol. 57, no. 1, January 2010, pp. 457 - 464 [4] S. Ayat, R. Wrobel, J. Goss, D. Drury, "Experiment Informed Methodology for Thermal Design of PM Machines," $11^{\text {th }}$ International Conference on Ecological Vehicles and Renewable Energies, EVER'2016, Monte Carlo, Monaco, April 2016, pp. 1 - 7 [5] P. A. Hargreaves, B. C. Mecrow and R. Hall, "Calculation of Iron Loss in Electrical Generators Using Finite-Element Analysis," IEEE Transactions on Industry Applications, vol. 48, no. 5, September-October 2012, pp. 1460 - 1466 [6] C. R. Sullivan, "Computationally Efficient Winding Loss Calculation with Multiple Windings, arbitrary waveforms, and two-dimensional or three-dimensional field geometry," IEEE Transactions on Power Electronics, vol. 16, no. 1, January 2001, pp. 142 - 150 [7] R. C. Pankhurst, D. W. Holder, "Wind-Tunnel Technique," Sir Isaac Pitman \& Sons, Ltd., London, 1968 [8] A. Hussein, “Additive Manufacturing of Compact Heat Exchangers," $34^{\text {th }}$ Heat Exchanger Action Group Meeting, HEXAG'2017, Newcastle upon Tyne, Newcastle University, June 2017 (www.hexag.org) [9] R. Wrobel, S. Ayat, J. Godbehere, "A Systematic Experimental Approach in Deriving Stator-Winding Heat Transfer," IEEE International Electrical Machines and Drives Conference, IEMDC'2017, Miami, FL, USA, May 2017, pp. 1 - 8 